\title{
Perception and utilization of public health services in Southeast Nigeria: Implication for health care in communities with different degrees of urbanization
}

\author{
Nkechi G. Onyeneho ${ }^{1,2^{*}}$, Uche V. Amazigo ${ }^{3}$, Ngozi A. Njepuome ${ }^{4}$, Obioma C. Nwaorgu ${ }^{5}$
} and Joseph C. Okeibunor ${ }^{1,6}$

\begin{abstract}
Background: The relationship between people's perception and utilization of public health serviceswas investigated.

Methods: A survey of 840 households across selected urban, peri urban and rural communities, in the Southeast of Nigeria, was conducted using the mixed methods approach.

Results: Of the nine (9) demographic variables, only the locality and status of the health system (strong or weak in terms of child immunization) was found to influence both the poor rating and utilization of public health services. Individuals from states with strong health system rated relatively higher and used public health services more $(p<$ 0.001), than their counterparts from states with weak health care system. Similarly, those in the urban or peri-urban localities used public health services more $(p=0.013)$. The two perceptual variables significantly influence the rating and use of public health services. Those with a good perception of the quality of health service provided, rated and patronized them more $(p<0.001)$. Also, health centres that provide a high number of services enjoyed greater rating and patronage ( $p<0.001$ and $p=0.0524$ respectively). The results of the structured questionnaire survey were confirmed by qualitative enquiry,based on in-depth interviews and focus group discussions.
\end{abstract}

Conclusions: It will be necessary to create a more responsive atmosphere in the health facilities, with culturallysensitive and friendly health workers, and provision of affordable drug to improve the perceptions of the primary health care system, for it to succeed in providing health services for all.

Keywords: Perception, utilization, health services, Nigeria

\section{Background}

Child and maternal deaths have experienced a significant reduction, reflecting progress towards the health-linked Millennium Development Goals (MDG) globally [1]. Between 1990 and 2013, global under-five mortality declined from 12.7 million to 6.3 million and maternal mortality ratio dropped from 380 to 210 per 100,000 live

\footnotetext{
* Correspondence: nkechi.onyeneho@unn.edu.ng

'Department of Sociology/Anthropology, University of Nigeria, Nsukka, Nigeria

${ }^{2}$ Takemi Program in International Health, Department of Global Health and Population, Harvard T.H, Chan School of Public Health, Harvard University, Boston, MA, USA

Full list of author information is available at the end of the article
}

births [2]. However, the proportion of child and maternal deaths recorded in sub-Saharan Africa increased [3]. In Nigeria, for instance, maternal mortality ratio increased from 545 to 575 deaths per 100,000 live births between 2008 and 2013 [4, 5], reflecting a worsening situation $[4,6]$. Interventions have been designed to reduce maternal mortality and achieve the MDG target of 250 or less deaths per 100,000 live births in Nigeria. Maternal and child health continue to worsen, despite the government's partnership with the private sector to promote improved access to quality maternal health services [6].

The current realities indicate that the huge global and national investments aimed at effective health care 
delivery have not yielded the desired results because of poor utilization and ultimately low access. According to Frost and Reich [7], availability of interventions and services does not translate automatically to access. Access implies effective and appropriate utilization of the interventions and services by the intended clientele. Poor access to health facilities and services was identified as a factor militating against efforts to address major health problems in Africa [8].

Gaps have also been revealed between need and actual access to some critical health services [4]. Sixty-one percent of mothers in Nigeria received antenatal care from a skilled provider. Of this proportion, only $51 \%$ made at least four antenatal care visits during pregnancy. This gives a $49 \%$ point drop in utilization between the first and fourth usage. In terms of child health, only $19 \%$ of the children (aged 12-23 months at survey time) received all the basic vaccinations as shown in the vaccination cards. The third of diphtheria, pertussis and tetanus (DPT3) vaccine, used as proxy for vaccine utilization, recorded only $22.2 \%$ use, whereas DPT1 was $26.7 \%$.

Perception has come up a prominent determinant of the utilization of health services. According to Roberts et al. [9], "...utilization is only partially a reflection of effective availability, as patients may choose not to use services, even if they are available". The decision to use available health services depends on people's perception of the services and affordability. People's perceptions and judgment are often conditioned by assessing factors their traditions and culture consider important such as courtesy, responsiveness, attentiveness, and perceived competence of the health staff [10]. Perceptions are determined by the people's level of satisfaction with the health service, as well as their assessment of the attitude of health workers, which often determines whether they would return in future. To achieve universal health for the people, it is imperative that all stakeholders understand the people's perception of health service, to ensure successful interventions. This is critical to developing appropriate promotional messages and campaigns, aimed at creating demand for particular health interventions [11].

Social-psychologists argue that perception, in the context of health, is structured on the basis of variables like 'risk perception' (the degree to which one feels susceptible to certain health risk), 'self-efficacy' (confidence in one's ability to take the necessary action) and 'action-outcome expectancies' (ones belief that the proposed action is contributory to the expected outcome) [12-18]. Others stressed that these variables tend to produce motivation to adhere to healthier behaviours (precautionary motivation) that may lead to an intention to carry out these behaviours $[19,20]$. It has also been argued that health care utilization is a function of both need-related factors as well as supply-induced and thus strongly dependent on the structures of the health care system [21]. Anderson's behavioural model captures these different domains aptly in its multilevel model that incorporates both individual predisposing factors and contextual or health provider determinants of health service use otherwise called enabling and need factors [22]. However, data on perceptions of health interventions and services have generally been collected quantitatively with comparatively low reliance on qualitative methods of inquiry [23-30]. This study adopted the mixed-method approach, in assessing the perceptions of people in Southeast Nigeria and how it influences their utilization of public health facilities and services (that is primary health care).

\section{Methods}

Study design

This study was designed for description and analysis of community perceptions and expectations of districtbased health care systems, in the South east geopolitical zone of Nigeria. Community perception of health and health care was assessed using a framework that recognizes interactions among a number of variables [31], such as the environmental and socio-demographic realities of the people, as well as their past experiences with the health system. See the Fig. 1. The framework accounts for past experiences with the PHC, in explaining the intermediate factors that influence perceptions and expectations from the PHC system. This multidisciplinary study combined two analytical designs, namely: 1) a crosssectional survey and 2) a qualitative inquiry. The survey research was based on an interviewer-administered household survey instrument (structured questionnaire) while the qualitative inquiry was based on in-depth interviews and focus-group discussion methods. These two designs contributed to an in-depth, triangulated understanding of community perceptions and perspectives of health systems in Southeast Nigeria.

\section{Study area}

Figure 2 shows that the Nigerian political structure comprises of thirty-six states and the Federal Capital Territory distributed into six geopolitical zones (GPZs). The South East GPZ (comprising of five states) is predominantly Igbo, one of the three largest ethnic-sociocultural groups in Nigeria. Beyond being culturally homogenous, the zone had the highest average zonal immunization coverage (66.9\%) in 2008 and $88.9 \%$ in 2013 [4].

States in the South East GPZ were grouped into two categories of "strong" (well performing) versus "weak" (less well performing) based on the zonal DPT3 coverage in the 2008 Nigeria Demographic and Health Survey [5]. Any state within the zone with less than the zonal average was classified as weak. Imo and Enugu States with 


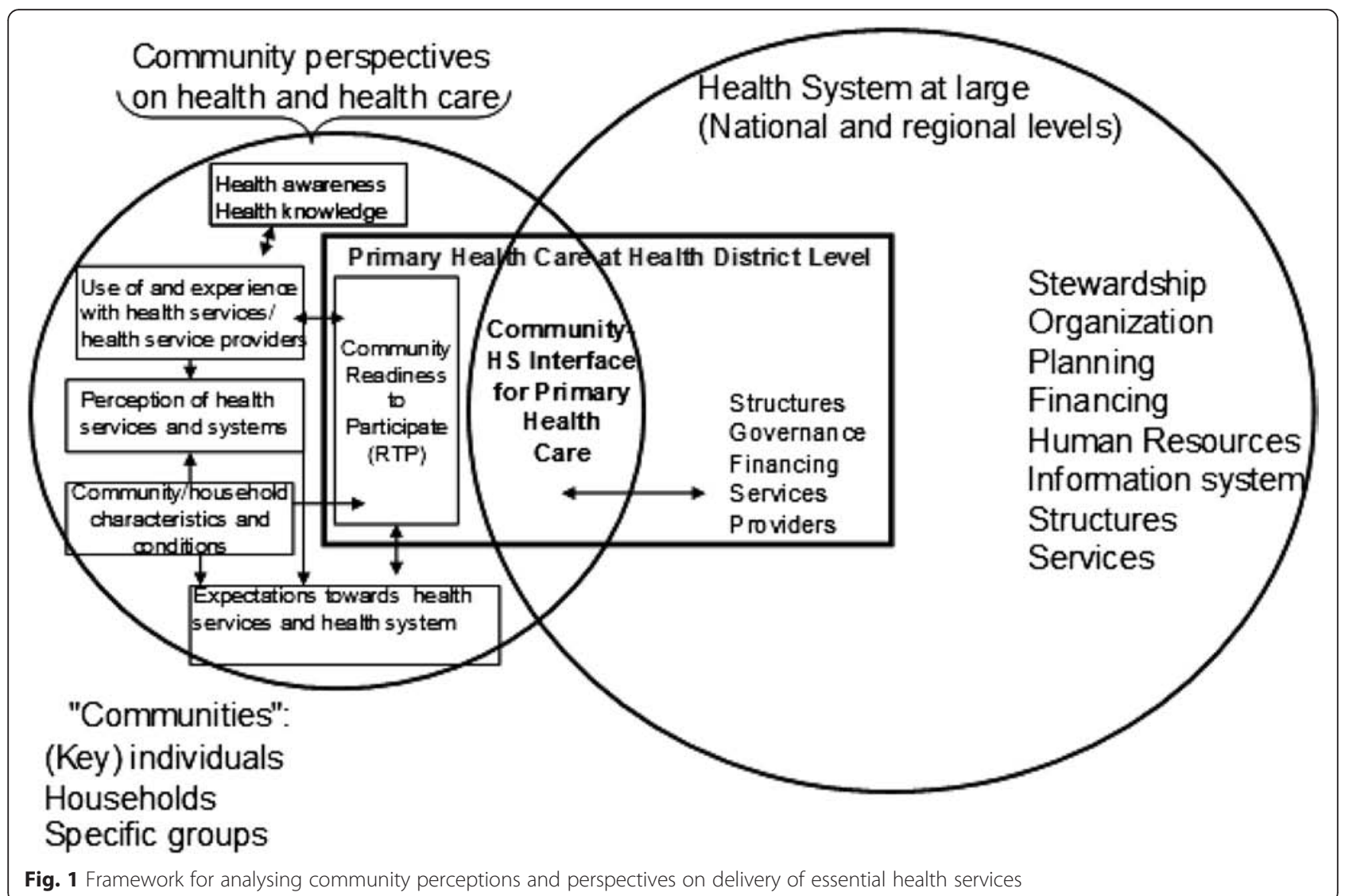

$77.0 \%$ and $50.0 \%$ were randomly selected as strong and weak performing states, respectively.

\section{Population and sampling}

The LGAs in each of the two selected states were classified and grouped into three clusters of rural, urban, and peri-urban. Three LGAs, one each from the urban, periurban, and rural segments of each sampled state, were randomly selected, for a total of six LGAs. From the list of communities in each sampled LGA, four communities were randomly selected. These formed the sampling clusters from which eligible respondents were drawn, following a two-stage sampling. The communities were grouped into two clusters of far $(>5 \mathrm{~km})$ and near $(<5 \mathrm{~km})$ to the LGA PHC center. Two communities were randomly selected from each cluster, yielding a total of twenty-four communities.

Using a $50 \%$ assumed rate of health services awareness and a confidence interval of $95 \%$ (estimated error margin of $3.5 \%$ ), a sample size of $770 \pm 27$ individuals was computed in the communities. The $50 \%$ rate gives the highest probability of inclusion of the population elements in the study thereby enhancing the representativeness of the sample [32]. However, the sample size was rounded up to 840 households, taking into account a $5 \%$ contingency rate. Approximately thirty-five household heads were interviewed in each of the twenty-four communities.

To select the households, a central location in each of the randomly selected communities was identified, which served as the starting point for data collection in the selected community. Two data collectors were assigned to cover each community cluster and the interviewers moved in opposite directions from the identified starting point in each community. Interviewers continued to turn right at every junction, until the desired number of respondents was attained. On occasions where the number required in any community was not reached, interviewers moved into an adjacent community to complete the number.

Community tradition heads were selected purposively for in-depth interview. Participants in the FGD were enlisted base on availability.

\section{Research instruments}

Six different research instruments were employed in the study, each targeting different sources of information for investigating the research questions. These instruments included household survey instrument administered to 35 heads of households in each of the 24 communities, four different guides for in-depth interviews with community leaders and representatives of community based organization, community health volunteers, and health 


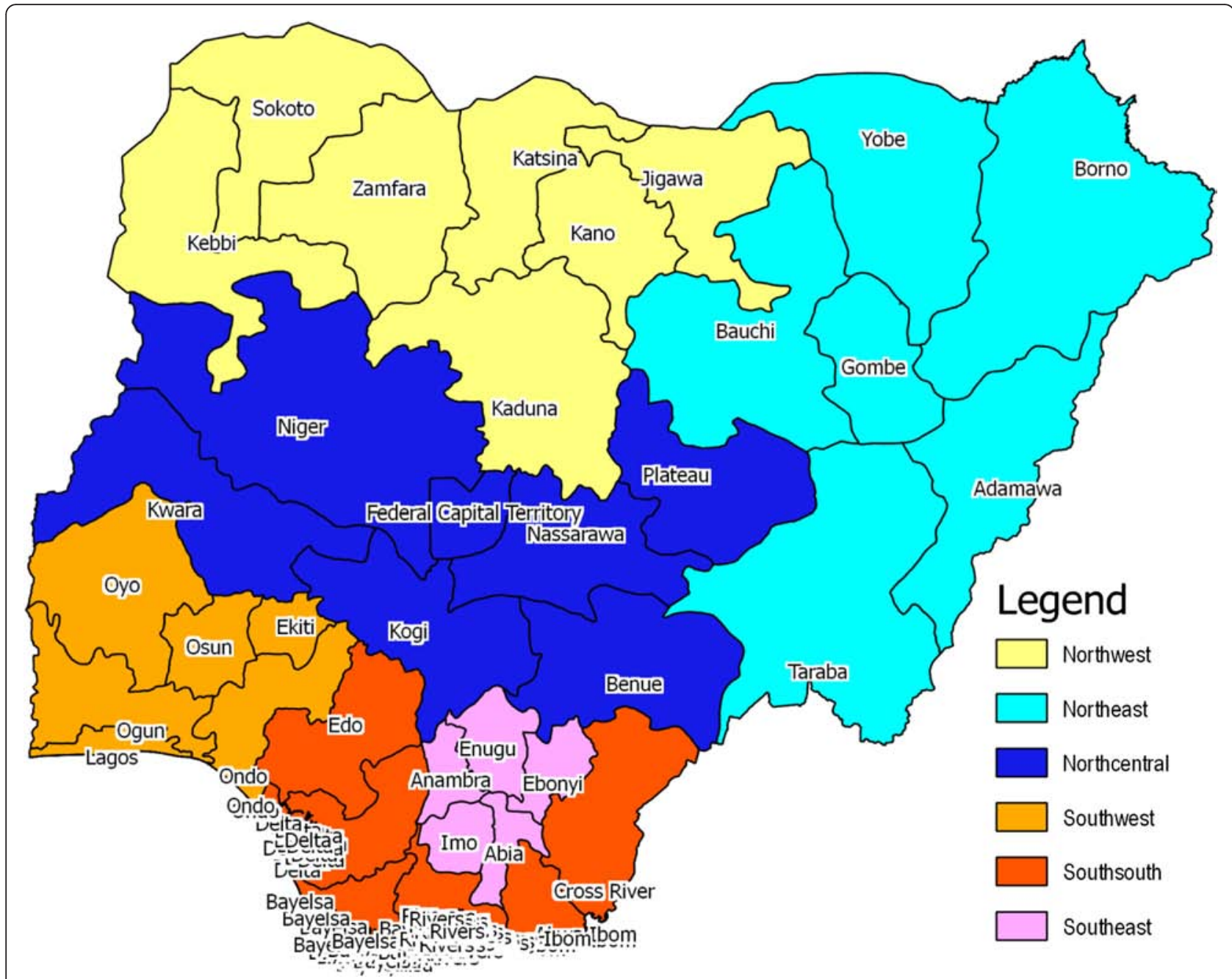

Fig. 2 Map of Nigeria six geopolitical zones and showing the study sites (Imo \& Enugu)

workers. Another set of instrument was the focus group discussion (FGD) guide. Twelve FGDs (three adult females and three adult males; three adolescent females and three adolescent males) with between eight and ten persons in each session were held in each health region. Each method had implications for different aspects of the study, unit of analysis and specific information about the needs of research questions.

\section{Data analysis}

All quantitative data were computer processed with EPI Info version 6 and analyzed with SPSS version 19. Simple descriptive statistics were employed in characterizing the respondents. However, multivariate analyses were also conducted to detect the predictive powers of certain demographic characteristics of the respondents on their perceptions of health systems in South East Nigeria.

Qualitative data consisted of textual data, mainly transcripts from interviews and discussion data. All qualitative data were analyzed using Atlas.Ti. All interviews were tape-recorded and detailed notes were taken simultaneously, including verbal citations. Tape-recorded interviews were transcribed according to standard rules and translated into English. All textual data were entered into Atlas.Ti software, and coded according to an established code list. Citations, by code and memos, were analyzed according to emerging themes using the network visualization abilities of the Atlas.TI software for qualitative analysis.

\section{Ethical approval}

The University of Nigeria Teaching Hospital Ethical Review Committee provided ethical approval for the conduct of the study.

\section{Results}

Socio-demographic characteristics

Table 1 summarizes the socio-demographic characteristics of the sample population. The mean age of the 
Table 1 Socio-Demographic Characteristics of Respondents by Locality (\% in Parentheses)

\begin{tabular}{|c|c|c|c|c|}
\hline \multirow{2}{*}{$\begin{array}{l}\text { Socio-demographic } \\
\text { Characteristics }\end{array}$} & \multicolumn{3}{|l|}{ Locality } & \multirow[t]{2}{*}{ Total } \\
\hline & Urban & Peri urban & Rural & \\
\hline \multicolumn{5}{|l|}{ Sex } \\
\hline Male & $202(72.1)$ & $226(80.7)$ & $195(69.6)$ & $623(74.2)$ \\
\hline Female & $78(27.9)$ & $54(19.3)$ & $85(30.4)$ & $217(25.8)$ \\
\hline \multicolumn{5}{|l|}{ Age } \\
\hline $25-34$ & $29(10.4)$ & $14(5.0)$ & $10(3.6)$ & $53(6.3)$ \\
\hline $35-44$ & $78(27.9)$ & $59(21.1)$ & $57(20.4)$ & $194(23.1)$ \\
\hline $45-54$ & $87(31.1)$ & 77 (27.5) & $82(29.3)$ & $246(29.3)$ \\
\hline $55-64$ & $46(16.4)$ & $69(24.6)$ & $64(22.9)$ & $179(21.3)$ \\
\hline $65+$ & $40(14.3)$ & $61(21.8)$ & $67(23.9)$ & $168(20.0)$ \\
\hline Mean & 49.16 & 53.25 & 54.02 & 52.15 \\
\hline STD & 12.03 & 12.16 & 12.44 & 12.38 \\
\hline Median & 48.00 & 53.00 & 52.00 & 50.00 \\
\hline Minimum & 26.00 & 30.00 & 30.00 & 26 \\
\hline Maximum & 85.00 & 90.00 & 92.00 & 92 \\
\hline \multicolumn{5}{|l|}{ Level of Education Attained } \\
\hline None & $44(15.7)$ & $36(12.9)$ & $75(26.8)$ & $155(18.5)$ \\
\hline Primary & $81(34.3)$ & $121(49.6)$ & $110(53.7)$ & $312(45.5)$ \\
\hline Secondary & $98(41.5)$ & $90(36.9)$ & $69(33.7)$ & $257(37.5)$ \\
\hline Post-Secondary & $41(17.4)$ & $31(12.7)$ & $19(9.3)$ & $91(13.3)$ \\
\hline Vocational & $15(6.4)$ & $2(0.8)$ & $7(3.4)$ & $24(3.5)$ \\
\hline Non Formal/Arabic & $1(0.4)$ & $0(0.0$ & $0(0.0)$ & $1(0.1)$ \\
\hline \multicolumn{5}{|l|}{ Income Generating Activities } \\
\hline None & $41(14.6)$ & $38(13.6)$ & $32(11.4)$ & $111(13.2)$ \\
\hline Farming/Fishing/Livestock & $32(13.4)$ & $47(19.4)$ & $71(28.6)$ & $150(20.6)$ \\
\hline Small Scale Trading & $54(22.6)$ & $34(14.0)$ & $47(19.0)$ & $135(18.5)$ \\
\hline Paid Employment & $37(15.5)$ & $46(19.0)$ & $34(13.7)$ & $117(16.0)$ \\
\hline Artisan & $56(23.4)$ & $63(26.0)$ & $48(19.4)$ & $167(22.9)$ \\
\hline Business & $56(23.4)$ & $41(16.9)$ & $42(16.9)$ & $139(19.1)$ \\
\hline Other & $4(1.7)$ & $11(4.5)$ & $6(2.4)$ & $21(2.9)$ \\
\hline \multicolumn{5}{|l|}{ Marital Status } \\
\hline Single & $5(1.8)$ & $7(2.5)$ & $3(1.1)$ & $15(1.8)$ \\
\hline Married & $215(76.8)$ & $212(75.7)$ & $188(67.1)$ & $615(73.2)$ \\
\hline Widowed & $51(18.2)$ & $49(17.5)$ & $76(27.1)$ & $176(21.0)$ \\
\hline Divorced & $6(2.1)$ & $10(3.6)$ & $8(2.9)$ & $24(2.9)$ \\
\hline Separated & $3(1.1)$ & $2(0.7)$ & $5(1.8)$ & $10(1.2)$ \\
\hline \multicolumn{5}{|l|}{ Religious Affiliation } \\
\hline Christian & $270(96.4)$ & $276(98.6)$ & $266(95.0)$ & $812(96.7)$ \\
\hline Muslim & $4(1.4)$ & $2(0.7)$ & $2(0.7)$ & $8(1.0)$ \\
\hline African Traditional Religion & $5(1.8)$ & $2(0.7)$ & $12(4.3)$ & $19(2.3)$ \\
\hline No Religion & $1(0.4)$ & $0(0.0)$ & $0(0.0)$ & $1(0.1)$ \\
\hline \multicolumn{5}{|l|}{ Length of Stay } \\
\hline$<1$ year & $3(1.1)$ & $2(0.7)$ & $1(0.4)$ & $6(0.7)$ \\
\hline $1-4$ years & $23(8.2)$ & $13(4.6)$ & $7(2.5)$ & $43(5.1)$ \\
\hline
\end{tabular}


Table 1 Socio-Demographic Characteristics of Respondents by Locality (\% in Parentheses) (Continued)

\begin{tabular}{|c|c|c|c|c|}
\hline $5-10$ years & $62(22.1)$ & $27(9.6)$ & $29(10.4)$ & $118(14.0)$ \\
\hline $11-20$ years & $60(21.4)$ & $56(20.0)$ & $54(19.3)$ & $170(20.2)$ \\
\hline$>20$ years & $132(47.1)$ & $182(65.0)$ & $189(67.5)$ & $503(59.9)$ \\
\hline Mean & 25.9 & 32.2 & 34.5 & 30.9 \\
\hline STD & 20.2 & 19.5 & 20.4 & 20.3 \\
\hline Median & 20.0 & 30.0 & 31.5 & 30.0 \\
\hline Min & 1 & 1 & 1 & 1 \\
\hline Max & 75 & 85 & 92 & 92 \\
\hline \multicolumn{5}{|l|}{ Source of Health Information } \\
\hline Radio & $142(50.7$ & $151(53.9)$ & $113(40.4)$ & $406(48.3)$ \\
\hline Television & $12(4.3)$ & $4(1.4)$ & $6(2.1)$ & $22(2.6)$ \\
\hline Pamphlets & $1(0.4)$ & $0(0.0)$ & $1(0.4)$ & $2(0.2)$ \\
\hline Billboard & $1(0.4)$ & $2(0.7)$ & $0(0.0)$ & $3(0.4)$ \\
\hline Community/town crier & $39(13.9)$ & $63(22.5)$ & $90(32.1)$ & $192(22.9)$ \\
\hline Friends \& Relatives & $33(11.8)$ & $26(9.3)$ & $15(5.4)$ & $74(8.8)$ \\
\hline Churches \& health centers & $44(15.7)$ & $32(11.4)$ & $54(19.3)$ & $130(15.5)$ \\
\hline Don't Know & $8(2.9)$ & $2(0.7)$ & $1(0.4)$ & $11(1.3)$ \\
\hline
\end{tabular}

respondents was 52.15 years $(52.15 \pm 12.38 \mathrm{SD})$, and over two-thirds $(80.1 \%)$ of them had lived in specific study sites for $\geq 11$ years; thus, were able to relate to community events and health service activities with confidence. The respondents are predominantly males with only $25.8 \%$ females. This is however not strange, given the predominance of male headed households in African communities. More than two-thirds of the respondents were married (73.2 \%) with a slightly higher proportion of the respondents in the rural communities (27.1\%) reporting widowhood. This could be due to the fact that the rural sample had a relatively higher proportion of older persons $(46.8 \%$ aged $55+(\mathrm{n}=280))$ compared to the urban and peri-urban sites. The main income generating activities include artisan (22.9\%), farming (20.6\%), followed by business (19.1\%), small scale trading $(18.5 \%)$ and paid employment $(16.0 \%)$. On the whole however, $86.8 \%$ of the respondents were engaged in at least one form of income activity or the other. The respondents were predominantly Christians (96.7\%) and $81.4 \%$ had received formal education. Radio was the commonest source of information (48.3\%), irrespective of the locality.

\section{Perception and utilization of health care services}

Figure 3 revealed the emphasis on child and maternal care, irrespective of the health system's strength. The inquiry on the people's perception of health services available in the community health facilities was opened with a question of on the services they think were provided in the health facilities. It was a free listing process which allowed respondents to list as many services as they could unprompted, while the research assistants recorded against the relevant precoded options in the questions. Where any service mentioned was not covered in the list of options, the research assistants entered the under the category 'other'. It was observed that care for the nutritional status patients, a major approach to maternal and child health care was very poorly represented in the services rendered in these facilities. Immunization and delivery services were also very poorly represented in the weak health system of the study. Generally, the perception of health services delivery was low, irrespective of the service or type of health system. Figure 2: Perceived health services provided by government health facilities in the communities.

Consequently, respondents in the study expressed poor perceptions of the general health services in the communities. More than half $(50.4 \%)$ the respondents rated health care services as bad, with the highest negative rating coming from rural dwellers (55.4\%), while peri-urban and urban respondents had an equally negative rating of $47.9 \%$ each.

A majority of the respondents demanded that drugs be provided in the health facilities $(74.9 \%)$. The highest proportion of respondents ( $80 \%)$, demanding that drugs be put in the health facilities, are from rural communities. Very high proportion $(73.2 \%, 61.4 \%$ and $63.2 \%$ ) of urban, peri urban and rural respondents respectively were dissatisfied with the health care services, irrespective of locality.

Drugs were unavailable in about two-thirds (64\%) of the cases that sought health care 30 days prior to the survey. The implication is that the patients had to buy the prescribed drugs from medicine vendors, at prices 


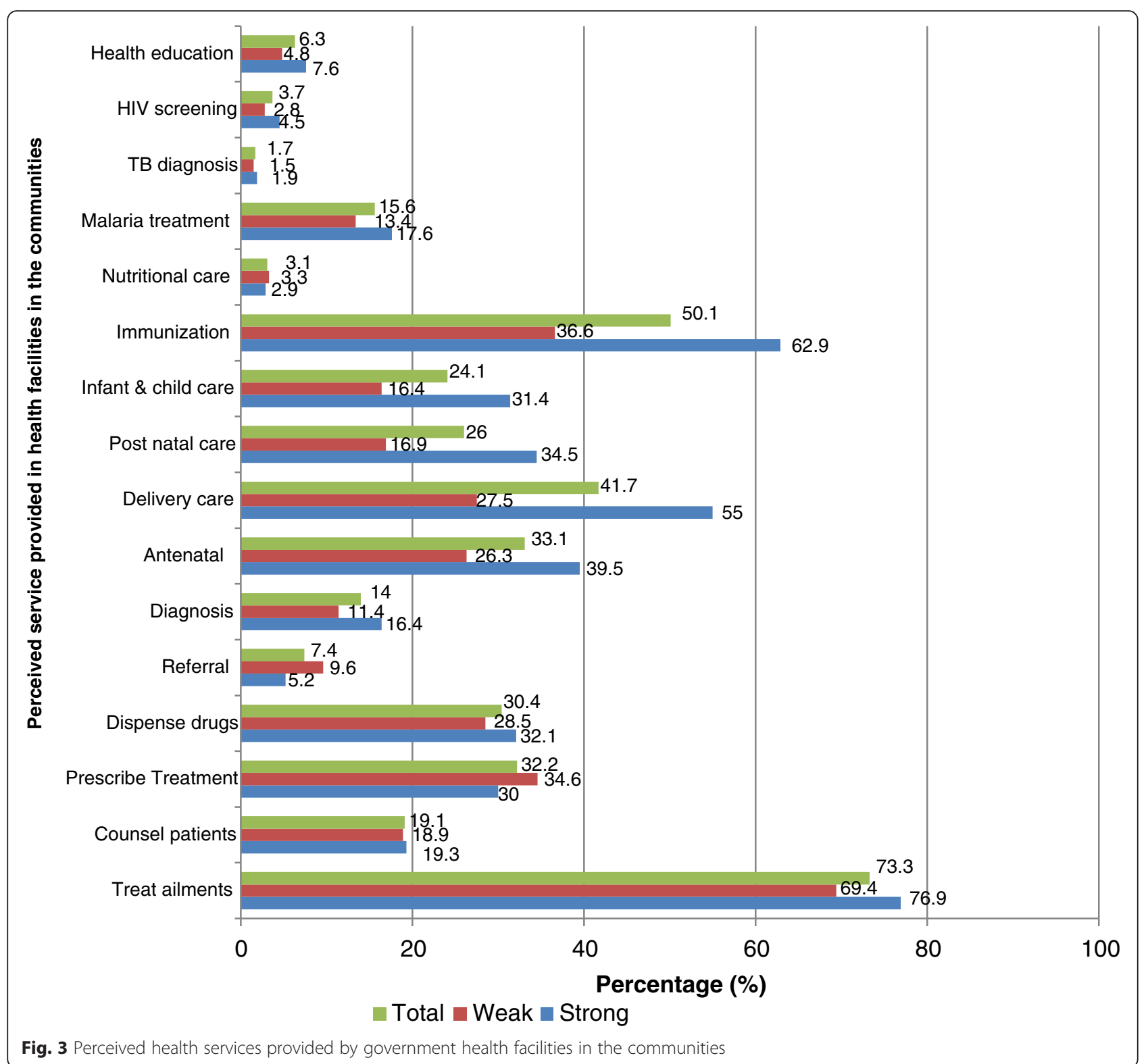

with profit mark-ups. In $7.3 \%$ of the cases, none of the prescribed drugs were available in the health facilities, with the rural communities being worst hit. About twothirds $(70.2 \%)$ of the respondents had to get drugs from medicine shops.

Generally, health service delivery was rated low ( $\leq 50 \%$ in many cases) in the community. This low rating cuts across the different social demographic backgrounds of the respondents. However, Table 2 shows that health care delivery in communities received a significantly higher rating $(p<0.001)$, among respondents from strong performing states. The results show that a significantly higher proportion of respondents from areas where health facilities are perceived to render more services, gave higher rating than their counterparts $(p<0.001)$.
In an interview, a patient summarized her frustration with poor services as follows:

...if I had gone to a private hospital, I would have paid more money, but would have saved my time. I would be paid attention because the workers know that I'm bringing in money. They would be here on time to do their jobs but here, it is not like that. It is only poverty that will bring me here again...

The respondents also differed in their perception of the number of services provided in health centres. For instance, more of the respondents $(41.0 \%)$ from areas where health centres are perceived to deliver more services, approved of the level of community involvement 
Table 2 Demographic and perceptual correlates of health service rating and use in the communities

\begin{tabular}{|c|c|c|c|c|c|c|}
\hline \multicolumn{3}{|l|}{ Characteristics } & \multicolumn{2}{|c|}{ Rating of Services of Health Facility } & \multicolumn{2}{|c|}{ Utilization of public health service } \\
\hline Factors & Category & Number & $\%$ Good Rating & $x^{2}$ Statistic; $p$ value & Use of health services & $x^{2}$ Statistic; $p$ value \\
\hline \multirow[t]{2}{*}{ State } & Strong & 420 & 63.1 & $X^{2}=145.84 ; P<0.001$ & 50.5 & 37.508 \\
\hline & Weak & 420 & 21.9 & & 29.8 & $<0.001$ \\
\hline \multirow[t]{2}{*}{ Proximity } & Near & 420 & 44.8 & $x^{2}=2.01 ; P=0.366$ & 40.7 & 1.523 \\
\hline & Far & 420 & 40.2 & & 32.1 & 0.138 \\
\hline \multirow[t]{3}{*}{ Locality } & Urban & 280 & 43.6 & $X^{2}=5.24 ; P=0.263$ & 33.6 & 8.751 \\
\hline & Peri urban & 280 & 44.6 & & 45.7 & 0.013 \\
\hline & Rural & 280 & 39.3 & & 41.1 & \\
\hline \multirow[t]{2}{*}{ Sex } & Male & 623 & 41.3 & $X^{2}=5.69 ; P=0.058$ & 40.4 & 0.110 \\
\hline & Female & 217 & 46.1 & & 39.2 & 0.402 \\
\hline \multirow[t]{2}{*}{ Education } & Formal & 685 & 43.4 & $X^{2}=1.53 ; P=0.466$ & 40.4 & 0.157 \\
\hline & Non formal & 155 & 38.7 & & 38.7 & 0.381 \\
\hline \multirow[t]{2}{*}{ Engage in Income Activity } & Yes & 729 & 41.4 & $X^{2}=3.29 ; P=0.193$ & 39.9 & 0.093 \\
\hline & No & 111 & 49.5 & & 41.4 & 0.418 \\
\hline \multirow[t]{5}{*}{ Length of Stay in the area (in years) } & $<1$ & 6 & 50.0 & $x^{2}=6.24 ; P=0.621$ & 16.7 & \\
\hline & $1-4$ & 43 & 51.2 & & 39.5 & \\
\hline & $5-10$ & 118 & 45.8 & & 41.5 & 1.735 \\
\hline & $11-20$ & 170 & 36.5 & & 38.5 & 0.784 \\
\hline & $>20$ & 503 & 42.9 & & 40.7 & \\
\hline \multirow[t]{2}{*}{ Age (in years) } & Young $(<50)$ & 368 & 43.2 & $X^{2}=0.22 ; P=0.897$ & 38.8 & 0.766 \\
\hline & Old (50+) & 472 & 41.9 & & 41.8 & 0.211 \\
\hline \multirow[t]{8}{*}{ Source of Health Information } & Radio & 406 & 45.4 & $x^{2}=17.41 ; P=0.235$ & 40.6 & \\
\hline & Television & 22 & 54.5 & & 50.0 & \\
\hline & Pamphlet & 2 & 50.0 & & 50.0 & \\
\hline & Billboard & 3 & 0.0 & & 33.3 & 11.130 \\
\hline & Town crier & 192 & 43.2 & & 45.8 & 0.133 \\
\hline & Friend/Relatives & 74 & 35.1 & & 32.4 & \\
\hline & Church/HF & 130 & 34.6 & & 35.4 & \\
\hline & Don't know & 11 & 54.5 & & 9.1 & \\
\hline \multirow[t]{2}{*}{ Number of Services in Health Centre } & Low (0-3) & 426 & 34.0 & $x^{2}=33.97 ; P<0.001$ & 37.3 & 2.822 \\
\hline & High (4-14) & 390 & 54.1 & & 43.0 & 0.054 \\
\hline \multirow[t]{3}{*}{ Perception of health service } & None existent & 463 & 0.0 & $X^{2}=789.18 ; P<0.001$ & 31.9 & 29.419 \\
\hline & Poor & 53 & 9.5 & & 47.2 & $<0.001$ \\
\hline & Good & 324 & 90.5 & & 50.8 & \\
\hline
\end{tabular}

in health service delivery $(p<0.001)$. Despite variations by locality, the results show that more of the respondents (49.0\%) from strong performing states were satisfied with health care delivery. Compared to their urban counterparts, respondents in peri-urban (38.6\%) and rural (32.6 \%) LGAs, were satisfied with health care delivery in their communities. During the exit interview, a patient had this to say, "an injection that I should have taken at 6 am, was given to me at 11:45 because of their lateness, that is what I mean".
The respondents seemed to have matched their perceptions with the use of government health facilities in their communities. About half (50.2\%) of the respondents indicated that they patronize health centres, about forty percent $(40.4 \%)$ mentioned patent medicine vendor, while the remaining $10 \%$ use other unorthodox means, for their health requirements. The peri urban area had the highest number of health centre users, while the least was from the urban area with 50.0 and $26.4 \%$, respectively. 
Health centres and patent medicine vendors were very popular for the management of different health problems, irrespective of location. For instance, $57.1 \%$ of the 840 respondents cited patent medicine vendors for the management of aches and pains while $40.1 \%$ cited health centres. The health centres were popular for health problems like difficulty in moving, difficulty in engaging in vigorous activities, difficulty in caring for oneself, and difficulty in recognizing people. However, health centres were less popular in rural areas than in the urban or peri urban areas.

Participants in the qualitative inquiry stated lack of responsive services in government health centres as the reason for their preference of patent medicine stores. Respondents in the qualitative study also complained of lack of drugs and the poor attitude of health centre workers. The statement below illustrates this point.

...It is heart breaking that when a sick person gets to the health centre, he or she will not get the drugs he needs.

[Participant: FGD, Adult Male in Imo, Peri Urban]

...the attitude of the health workers does not help matters. They treat us with no respect. In many cases, they respond to you based on their estimation of your social standing or wealth. The poor are ignored for the rich and even where they attend to you, they are very rude.[Participant: FGD, Adult Female in Enugu, Rural]

About a third (39.6\%) of the respondents had just one health care facility to visit. More of the urban respondents sought health care from private hospitals/clinics.

When they are really sick, they look out for hospitals with qualified medical doctors... and other specialist medical personnel, whom they will not find at the primary health centres.... [Respondent: IDI; Health Worker in Owerri, Imo State]
In the weak performing state however, a community leader in Ezeagu said,

... because we don't have a good hospital here, when people are sick they go to the bush and start looking for leaves and roots to boil and drink or they will go to the chemist to buy drugs that may be fake or just pray for the sickness to go away in God's time...

Table 2 shows low rates of use across different categories of the socio-demographic realities, with the exception of their state of origin and perceptions of health services. Respondents from Imo state, who were classified as having a strong health system, tended to use government health facilities more than their counterparts from Enugu State $(\chi 2=37.508 ; \mathrm{p}<0.001)$. Similarly, those who perceived government health facilities to deliver a higher number of services tended to use the facilities more than their counterparts $(p=0.054)$. Also, individuals with a generally good perception of government health systems and services greatly used the facilities ( $\mathrm{p}<0.001)$.

Further analysis of the data was conducted using a logistic regression of the rating and utilization of government health facilities, using the socio-demographic characteristics of the respondents, as well as their perception of the health systems and services, as independent variables. Each independent variable in the regression models was converted into a dummy variable where the presence of a desired category was recorded as ' 1 ' and the presence of an alternative recorded as ' 0 '. The categories with higher scores were entered as the substantive and recorded as ' 1 ' while the other categories were coded as ' 0 '. For instance, the results in Table 2 shows that more peri-urban residents rated the health services as good and patronized them. Hence, the peri urban category was coded as ' 1 ', while the rural and urban categories were coded as ' 0 '. The results are as shown in Table 3.

Table 3 Regression of Respondents' socio-demographic characteristics and perception of health service on rating and utilization of health facilities in the communities

\begin{tabular}{|c|c|c|c|c|}
\hline \multirow{2}{*}{$\begin{array}{l}\text { Socio-demographic and perceptual } \\
\text { characteristics }\end{array}$} & \multicolumn{2}{|c|}{ Rating of services in health facility } & \multicolumn{2}{|c|}{ Utilization of health facility } \\
\hline & B coefficient & $P$ value & B coefficient & $P$ value \\
\hline Age $(50$ years +$)$ & -0.570 & 0.142 & 0.180 & 0.240 \\
\hline Education (Formal) & 0.347 & 0.502 & 0.005 & 0.978 \\
\hline Residence (peri urban) & 0.905 & 0.013 & 0.442 & 0.005 \\
\hline Sex (male) & 0.167 & 0.702 & 0.081 & 0.629 \\
\hline Income (Engage in income generation) & -0.006 & 0.992 & -0.072 & 0.740 \\
\hline Perception of health service (Good) & 0.357 & 0.324 & 0.698 & 0.000 \\
\hline Number of services in health centre (High) & 24.021 & 0.991 & 0.096 & 0.513 \\
\hline Constant & -3.390 & 0.000 & -0.666 & 0.014 \\
\hline
\end{tabular}


Table 3 shows that variables in the two models, collectively influence the rating and utilization of health systems significantly $(\mathrm{p}<0.001$ and $\mathrm{p}=0.014$, respectively). However, only the place of residence (urban, peri urban or rural) contributed significantly to the capabilities of the regression models, in explaining the rating or utilization of health facilities in the communities. It shows that a unit increase in urbanization will lead to a $1.3 \%$ point increase in the rating of the health facilities and $5 \%$ increase in utilization. Similarly, a unit increase in the perception will lead to a $69.8 \%$ point increase in health facilities utilization.

\section{Discussion}

The general perception of health facilities service was poor across all the study areas (urban, peri-urban and rural). There was a general dissatisfaction with health care delivery based on the high cost of services in the rural and urban areas while the peri-urban area reported satisfaction with service delivery. The common health problems in all the study districts were malaria and fever. The signs of good health were based on physical activities such as the ability to work and move around. This poor understanding of the definition of health could be attributed to their level of education and exposure. The respondents viewed staying healthy as a product of healthy feeding, hygiene, sanitation and regular check-ups. All of which are in line with standards of best health practices.

The results of this study have not only corroborated previous studies on the impact of perception on health behavior, it also revealed significant association between the perceptions people hold of the quality and quantity of health services available in their various community health facilities and the use of such health facilities for any services. The people perceived community health facilities useful in the treatment of ailments, and prescription of drugs, but were grossly lacking in most preventive services, such as maternal and child health care among others.

The people often resorted to patent medicine vendors. Patent medicines are drugs that are allowed to be sold over the counter (OTC) that the Nigerian regulatory authorities, such as the Pharmaceutical Council of Nigeria (PCN), adjudge safe for unsupervised public use, as long as they are sold in their original manufacturer [32-36]. OTC drugs include common drugs like pain relieving tablets, antimalarials, cough syrups and so forth [36].

In many cases, community members who received care got prescriptions sourced from patent medicine stores. Nishtar [37] documented similar scenarios in his appraisal of health care delivery in African countries. He reported that in developing and underserved areas, a mixed health system characterized by government and private sector partnership, in which out-of-pocket payments and market provisions of services co-exists with publicly financed government health centres, is the norm.

Solutions to these health problems were sought mainly from government and private hospitals outside the study districts. However, ailments such as mental illness and convulsions were not taken to the hospitals. Patients with such ailments were mostly taken to traditional and spiritual healers, based on the cultural beliefs of the respondents. The household heads were mainly responsible for ensuring good health in the community, irrespective of district classification. This is not unusual in the African setting where men play significant roles in decision making.

Experiences of community engagement with the health system were facilitated by the avenues through which information reached them. The major source of information was the radio $(48.3 \%)$ followed by community announcement $(22.9 \%)$. There was no barrier to information on health and health service delivery; thus, suggesting good awareness on health issues. This was also confirmed by community involvement and participation in health issues, irrespective of the districts.

A comparative analysis of how information source influenced perceptions, revealed no difference with respect to perceptions on services of health facilities in the communities; community involvement and satisfaction with the way health care is provided in the communities. Similarly, the source of health information did not influence the perception of the adequacy of government contributions to community health. All of these point to a general low perception of the performance of the health system and government, in terms of health care delivery in the communities. However, with respect to the contributions of the communities, the source of health information affected perceptions significantly. In conclusion, the findings of the study revealed a poor community perception of health. The respondents in this study rated health systems poorly. Community expectations and responsiveness to health service delivery were not met. Health care delivery was hindered by lack of health facilities in some communities, shortage of commodities, and inaccessibility especially during the rainy season, as well as lack of basic amenities in the communities. Communities (urban, peri urban and rural) expressed disappointment for the grossly inadequate health care services available to them, characterized by acute shortage of drugs, poor attitude of health workers and lack of health insurance.

\section{Conclusions}

There is widespread poor community perception of health irrespective of the tyoe of community. Community expectations of the heakth service seem largely unmet in an apparent weak healthsystem. A number of constraints to the functionality of the health system were 
highlighted to include lack of health facilities in some communities, shortage of commodities, and inaccessibility especially during the rainy season, as well as lack of basic amenities in the communities.

\section{Acknowledgements}

This paper resulted from a study which was implemented with funding from the World Health Organization African Programme for Onchocerciasis (WHO/ APOC) and the World Health Organization Regional Office for Africa (WHO/ AFRO), Brazzaville, Republic of Congo.

\section{Author details}

'Department of Sociology/Anthropology, University of Nigeria, Nsukka, Nigeria. ${ }^{2}$ Takemi Program in International Health, Department of Global Health and Population, Harvard T.H, Chan School of Public Health, Harvard University, Boston, MA, USA. ${ }^{3}$ P.O.Box 3397Main Post Office, Okpara Avenue, Enugu, Nigeria. ${ }^{4}$ P.O.Box 7117Wuse, Abuja, Federal Capital Territory, Nigeria. ${ }^{5}$ Department of Parasitology, Nnamdi Azikiwe University, Awka, Nigeria. ${ }^{6}$ Immunization, Vaccines and Emergencies, WHO Regional Office for Africa, Brazzaville, Congo.

\section{Received: 10 September 2015 Accepted: 5 January 2016}

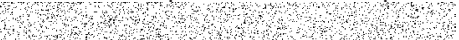

\section{References}

1. National Population Commission. National policy on population for sustainable development. Abuja: National Population Commission; 2004.

2. United Nations. We can end poverty. UN Web Section. www.un.org/en/ mdg/summit2010/calendar.shtml. Accessed on December 12, 2014.

3. United Nations Economic Commission for Africa. Report on progress in achieving the Millennium Development Goals in Africa. Addis Ababa: United Nations Economic Commission for Africa; 2013.

4. National Population Commission (NPC) [Nigeria] and ICF International. Nigeria Demographic and Health Survey 2013. Abuja, Nigeria, and Rockville, Maryland, USA: NPC and ICF International; 2014.

5. National Population Commission (NPC) [Nigeria] and ICF Macro. Nigeria Demographic and Health Survey 2008. Abuja, Nigeria, and Maryland, USA: NPC and ICF Macro; 2009.

6. Federal Republic of Nigeria [Nigeria]. Countdown strategy 2010 to 2015, Millennium Development Goals (MDGs). Abuja: Government of the Federal Republic of Nigeria; 2010

7. Frost L, Reich MR. Access: How do Good Health Technologies Get to Poor People in Poor Countries. Cambridge: Harvard Center for Population and Development Studies; 2008.

8. WHO. Community-directed interventions for major health problems in Africa: a multi-country study: final report. 2008. http://apps.who.int/tdr/svc/ publications/tdr-research-publications/community-directed-interventionshealth-problems

9. Roberts MJ, Hsiao W, Berman P, Reich MR. Getting Health Reform Right: A guide to improving performance and equity. New York: Oxford University Press; 2008.

10. Singh $H$, Haqq ED, Mustapha N. Patients' perception and satisfaction with healthcare professionals at primary care facilities in Trinidad and Tobago. Bull World Health Organ. 1999;77(4):356-60.

11. Dowler E, Green J, Bauer M, Gasperoni G. Assessing public perception: Issues and methods. In: Carlos D, editor. Health, hazards and public debate: lessons for risk communication from BSE/CJD Saga. Geneva: WHO; 2006. p. $40-60$.

12. Armitage CJ, Conner M. Social cognition models and health behaviour: A structuredreview. 2007. p. 37-41.

13. Conner M, Sparks P. The theory of planned behaviour and health behaviours. In: Conner M, Norman P, editors. Predicting health behaviour. Buckingham: Open University Press; 1996. p. 121-62.

14. Witte K. Fear control and danger control: A test of the extended parallel process mode. Commun Monogr. 1994;61:113-34.

15. Schwarzer R. Self-efficacy in the adoption and maintenance of health behaviors: Theoretical approaches and a new model. In: Schwarzer R, editor. Self-efficacy: Thought controlof action. Washington, DC: Hemisphere; 1992. p. 217-43.
16. Rosenstock IM, Strecher VJ, Becker MH. Social learning theory and the Health Belief Model. Health Educ Q. 1988:15:175-83.

17. Bandura A. Social foundations of thought and action: A social cognitive theory. Rockville: National Institute of Mental Health; 1986.

18. Rosenstock IM. Historical origins of the health belief model. Health Educ Monogr. 1974;2:328-35.

19. Isa A, Loke YK, Smith JR, Papageorgiou A, Hunter PR. Mediational effects of self-efficacy dimensions in the relationship between knowledge of dengue and dengue preventive behavior with respect to control of dengue outbreaks: a structural equation model of a cross-sectionalsurvey. PLoS Negl Trop Dis. 2013;7:e2401.

20. Ruiter RA, Abraham C, Kok G. Scary warnings and rational precautions: a review of thepsychology of fear appeals. Psychol Heal. 2001;16:613-30.

21. Babitsch B, Gohl D, von Lengerke T. Re-visiting behavioural model of health services use: a systematic review of studies from 1998-2011. Psychosoc Med. 2012;9:Doc 11

22. Andersen RM, Davidson PL. Improving access to care in America: individual and contextual indicators. In: Andersen RM, Rice TH, Kominski EF, editors. Changing the U.S. health care system: key issues in health services, policy, and management. San Francisco: Jossey-Bass; 2001. p. 3-30.

23. Chinnakali P, Gurnani N, Upadhyay RP, Parmar K, Suri TM, Yadav K. High level of awareness but poor practices regarding denque fever control: a cross-sectional study from North India. NAm J Med Sci. 2012;4:278-82.

24. Pell C, Straus L, Andrew EV, Meñaca A, Pool R. Social and cultural factors affecting uptake of interventions for malaria in pregnancy in Africa: a systematic review of the qualitative research. PLoS One. 2011:6(7):e22452. doi:10.1371/journal.pone.0022452. Epub 2011 Jul 20.

25. Itrat A, Khan A, Javaid S, Kamal M, Khan H, Javed S, et al. Knowledge, awareness and practicesregarding dengue fever among the adult population of dengue hit cosmopolitan. PLoS One. 2008;3:e2620.

26. Greenwood B, Alonso P, ter Kuile F, Hill J, Steketee R. Malaria in pregnancy: priorities for research. Lancet Infect Dis. 2007;7:169.

27. Muela Ribera J, Hausmann-Muela S, D'Alessandro U, Grietens K. Malaria in pregnancy: What can the social sciences contribute? PLoS Med. 2007;4:631.

28. Koenraadt CJM, Tuiten W, Sithiprasasna R, Kijchalao U, Jones JW, Scott TW. Dengue knowledge and practices and their impact on Aedesaegypti populations in Kamphaeng Phet, Thailand. Am J Trop Med Hyg. 2006;74: 692-700.

29. Williams $\mathrm{H}$, Jones $\mathrm{C}$. A critical review of behavioral issues related to malaria control in sub-Saharan Africa: what contributions have social scientists made? Soc Sci Med. 2004;59:501-23.

30. McCombie S. Treatment seeking for malaria: A review of recent research. Soc Sci Med. 1996:43:933-45.

31. WHO/AFRO. Delivery of essential health services in the African Region Brazzaville, Congo. 2012.

32. Lemeshow S, Hosmer DW, Lwanga SK. Adequacy of sample size in health studies. New York: John Wiley \& Sons; 1990

33. Okonkwo AD, Okonkwo UP. Patent medicine vendors, community pharmacists and STI management in Abuja, Nigeria. Afr Health Sci. 2010; 10(3):253-65.

34. Onyeneho NG, Chukwu JN. Is there a role for patent medicine vendors in tuberculosis control in Southern Nigeria? J Health Popul Nutr. 2010; 28(6):567-77.

35. Brieger W, Unwin A, Greer G, Meek S. Interventions to improve the role of medicine sellers in malaria case management for children in Africa. London, UK and Arlington, Va., USA: the Malaria Consortium and BASICS for the United States Agency for International Development; prepared for Roll Back Malaria's Sub-group for Communication and Training and Malaria Case Management Working Group; 2005.

36. Ross-Degnan D, Goel P, Berman P, Soumeari S. Retail pharmacies in developing countries: A behaviour and intervention framework. Soc Sci Med. 1996;42(8):1155-61.

37. Egboh A. Pharmacy laws and practice in Nigeria. Ikeja: Literamed Publications: 1984 